\title{
Efficacy of quetiapine in patients with bipolar I and II depression: a multicenter, prospective, open-label, observational study
}

This article was published in the following Dove Press journal:

Neuropsychiatric Disease and Treatment

8 February 2013

Number of times this article has been viewed

\author{
Jong-Hyun Jeong' \\ Won-Myong Bahk' \\ Young Sup Woo' \\ Ho-Jun Seo' \\ Seung-Chul Hong' \\ Duk-In Jon ${ }^{2}$ \\ Kyung Joon $\mathrm{Min}^{3}$ \\ Bo-Hyun Yoon ${ }^{4}$
}

'Department of Psychiatry, College of Medicine, The Catholic University of Korea, Seoul, ${ }^{2}$ Department of Psychiatry, College of Medicine, Hallym University, Anyang,

${ }^{3}$ Department of Neuropsychiatry, College of Medicine, Chung-Ang University, Seoul, ${ }^{4} \mathrm{Naju}$ National Hospital, Naju, Korea
Correspondence: Won-Myong Bahk Department of Psychiatry, The Catholic University of Korea, 62, Yeoido-dong, Yeongdeungpo-gu, Seoul, Korea

Tel +82 23779 I05I; +82 237791735

Fax +82 27806577

Email wmbahk@catholic.ac.kr
Purpose: To evaluate and compare the therapeutic efficacy of quetiapine in bipolar I and II depression patients in the clinical setting.

Patients and methods: This was an 8-week, multicenter, open-label, observational study for bipolar depression. The dosage of quetiapine was flexible, and concomitant medications were permitted on clinician's judgments. A total of 1097 patients were enrolled, and 764 bipolar depression patients who exhibited good therapeutic compliance ( $>75 \%$ compliance rate) were analyzed.

Results: Clinical Global Impression - Bipolar scale and Montgomery-Asberg Depression Rating Scale scores were significantly improved at weeks four and eight compared with the baseline scores. At the end of the 8-week study, the response rate was $58.9 \%$, and the remission rate was $42.1 \%$. However, there were no significant differences in the response and remission rates between bipolar I and II disorder (BD-I and BD-II) patients (response rate $60.1 \%$ versus $56.3 \%$; remission rate $44.5 \%$ versus $37.0 \%)$. Montgomery-Asberg Depression Rating Scale score at baseline $(\beta=0.612$, $P<0.001)$, duration of current episode $(\beta=-0.152, P=0.001)$, and presence of remission on previous episode $(\beta=0.111, P=0.012)$ were significantly associated with improvements in depressive symptoms. Fatigue (16.0\%), somnolence (14.9\%), and manic/hypomanic switching $(0.6 \%$ at week four, $0.3 \%$ at week eight) were observed throughout the study period.

Conclusion: The results of this study suggest that quetiapine improves depressive symptoms in BD-I and BD-II patients with a minimal incidence of manic switching. The therapeutic efficacy of quetiapine increased with time. Quetiapine could be an effective and safe modality for the treatment of BD-I and BD-II.

Keywords: bipolar depression, quetiapine, therapeutic efficacy, observational study

\section{Introduction}

The lifetime prevalence of bipolar disorder (BD) is approximately 3\%-5\%, and $80 \%-90 \%$ of all BD patients experience depressive symptoms. ${ }^{1,2}$ In patients with BD, depressive periods tend to last longer than manic periods. ${ }^{3}$ In addition, a study that examined the symptoms experienced by BD patients over a 6-month period reported that approximately $60 \%$ of BD patients experienced depressive symptoms, which is two-fold higher than the incidence of manic symptoms. ${ }^{4}$ In other words, the period of depressive symptoms lasts longer, and the incidence of depressive symptoms is higher than that of manic symptoms. However, bipolar depression does not respond well to treatment; it frequently progresses to recurrent episodes of mood disorder, making it difficult to treat. The most widely used psychopharmacologic strategies for the treatment of bipolar depression include mood stabilizer monotherapy, a combination of mood stabilizers, and combination therapy with antidepressants. However, most recently, 
monotherapy with atypical antipsychotics, combination therapy with antidepressants, and combination therapy with mood stabilizers have been newly recommended..$^{5-10}$

Atypical antipsychotics are approved for the treatment of schizophrenia and psychotic disorders. However, due to their mechanism of action, they have been widely used to improve depressive symptoms in patients with psychotic disorders and BD. ${ }^{7}$ In particular, quetiapine has been known to exert antidepressant effects in patients with psychotic disorders and depressive symptoms. ${ }^{11}$ In two recent large-scale, double-blind, randomized controlled trials, quetiapine monotherapy was proven to have significantly higher antidepressant effects than placebo on bipolar I and II disorder (BD-I and $\mathrm{BD}-\mathrm{II})$, rapid cycling $\mathrm{BD}$, and depression with anxiety symptoms. Moreover, the risk of inducing manic symptoms with quetiapine monotherapy was not higher than that with placebo. These results indicate that quetiapine could be used as a first-line drug for the treatment of bipolar depression. ${ }^{12,13}$ Quetiapine was the first antipsychotic to be approved as a monotherapeutic agent for bipolar depression, not only by the US Food and Drug Administration but also by the Korean Food and Drug Administration.

However, the previous data were obtained using highly selective patients with many prescription restrictions, which could be different from actual clinical situations. In addition, no published large-scale data have evaluated the efficacy of quetiapine in BD patients in clinical settings.

Therefore, this observational study was conducted to evaluate the therapeutic efficacy of quetiapine, which was administered for 8 weeks to patients with BD-I, most recent episode depressed, and $\mathrm{BD}-\mathrm{II}$, most recent episode depressed.

\section{Material and methods Subjects}

This multicenter study was conducted at 98 sites including university hospitals and mental hospitals in Korea from June 1, 2007 to February 28, 2008. The study subjects were older than 18 years, and all subjects were diagnosed with BD-I, most recent episode depressed, or BD-II, most recent episode depressed, according to the diagnostic criteria of the Diagnostic and Statistical Manual of Mental Disorder, Fourth Edition, Text Revision (DSM-IV-TR). ${ }^{1}$ The study procedure was explained to the patients who participated in this study, and only patients who submitted a written consent form were allowed to participate. Because this study was an observational study conducted in an actual clinical setting, special exclusion criteria were absent, excluding rapid cycling, and even patients with chronic diseases were allowed to participate in the study, provided they were stable based on their past history and physical examination. However, patients with severe, unstable, or acute diseases as well as those with chronic physical illnesses were excluded from the study. The study protocol was approved by an institutional review board.

\section{Medication administration}

In this study, the dose of quetiapine was flexible depending on the clinical situation. In addition, the administration of concomitant medications was not restricted. Furthermore, even medications that had been continuously administered under stable conditions without a change in dose for the treatment of physical illnesses were allowed during the study period. To evaluate therapeutic compliance, the actual uptake of drugs was examined at weeks four and eight.

\section{Evaluation of therapeutic efficacy and compliance}

The Clinical Global Impression - Bipolar (CGI-BP) scale and Montgomery-Asberg Depression Rating Scale (MADRS) were used to evaluate therapeutic efficacy. ${ }^{14,15}$ Therapeutic efficacy was evaluated prior to the administration of quetiapine and after 4 and 8 weeks of administration.

As the main outcome measure of therapeutic efficacy, the CGI-BP and MADRS scores were compared at baseline and after 8 weeks of drug administration. In addition, the response rate ( $\geq 50 \%$ reduction in the total MADRS value) and remission rate ( $\leq 10$ in the total MADRS value) were examined at the 4- and 8-week time points. In addition, differences in therapeutic efficacy between the BD-I and BD-II patients were examined. In addition, the numbers of patients in each CGI-BP subgroup at baseline and after 4 and 8 weeks were compared.

To evaluate therapeutic compliance, the subjective level of therapeutic compliance was examined after 4 and 8 weeks of drug administration. The patients were divided by compliance rate as follows: $>75 \%, 50 \%-75 \%, 25 \%-50 \%$, and $<25 \%$.

\section{Data analysis}

Of the patients who completed the baseline evaluation prior to drug administration, patients who took quetiapine more than once and patients who were evaluated at least once after drug administration were included in the intent-to-treat group. The data were analyzed by the last observation carried forward method. Regarding the statistical methods, repeated 
measures of analysis of variance, Cochran-Mantel-Haenszel test, and the multiple linear regression test were applied. The independent $t$-test and Chi-squared test were used for comparisons of BD-I and BD-II patients, and all statistical analyses were performed with SPSS ${ }^{\circledR} 18.0$ (IBM Corporation, Armonk, NY). The level of statistical significance was set at $P<0.05$.

\section{Results}

\section{Demographic data and clinical characteristics}

A total of $1097 \mathrm{BD}$ patients were recruited for participation in this study, and 1058 patients (96.4\%) completed the entire study. To elucidate the true efficacy of quetiapine, patients who exhibited poor therapeutic compliance $(<75 \%$ compliance rate) after 4 or 8 weeks were excluded $(n=333)$. Thus, the study finally included 764 BD patients (mean age: $42.7 \pm 15.6$ years) consisting of 526 patients with BD-I (mean age: $41.1 \pm 14.7$ years) and 238 patients with BD-II (mean age: $46.3 \pm 16.9$ years); the difference in age between the BD-I and BD-II groups was significant $(P<0.001)$.

The mean duration of current depressive episode was $6.3 \pm 8.8$ weeks and duration of current episode was $7.9 \pm 12.1$ weeks in BD-II patients, which was significantly longer than in BD-I patients $(5.6 \pm 6.7$ weeks; $P=0.006)$.

Psychiatric comorbidity was detected in $3.8 \%$ of the subjects (BD-I 2.7\% versus BD-II 6.3\%; $P=0.015$ ). Approximately $33 \%$ of BD patients $(\mathrm{n}=250)$ were admitted (BD-I 35.7\% versus BD-II 26.1\%; $P=0.008$ ), and mean number of admissions was $3.1 \pm 1.9$ (BD-I $3.1 \pm 1.9$ versus BD-II $3.2 \pm 2.1$; not significant) (Table 1).

\section{Quetiapine dose and level of psychotropic concomitant medications}

The mean dose of quetiapine was initially $197.5 \pm 182.5 \mathrm{mg} /$ day, and it was gradually increased to $349.0 \pm 231.5 \mathrm{mg} /$ day by week eight. During all observation periods, the dose of quetiapine was significantly higher in the BD-I patients than in BD-II patients $(P<0.001)$ (Table 2$)$.

The combined administration of psychotropic agents was abundant in BD patients, and the difference in total concomitant medications administered between the BD-I and BD-II groups was not significant. Nonetheless, mood stabilizers (61.0\% versus $35.7 \% ; P<0.001)$ were administered more frequently in BD-I patients, but anxiolytics $(22.8 \%$ versus $31.5 \% ; P=0.001)$, antidepressants $(12.4 \%$ versus $42.47 \%$; $P<0.001)$, and hypnotics/sedatives $(8.0 \%$ versus $13.4 \%$;
Table I Demographic data and clinical characteristics of patients with bipolar I and II disorder

\begin{tabular}{|c|c|c|c|c|}
\hline & $\begin{array}{l}\text { Total } \\
(n=764)\end{array}$ & $\begin{array}{l}\text { BD-I } \\
(n=526)\end{array}$ & $\begin{array}{l}\text { BD-II } \\
(n=238)\end{array}$ & $P$-value \\
\hline \multicolumn{5}{|l|}{ Sex } \\
\hline Male & $298(39.0)$ & $210(39.9)$ & $88(37.0)$ & NS \\
\hline Female & $466(61.0)$ & $316(60.1)$ & $150(63.0)$ & NS \\
\hline Age (years) & $42.7 \pm 15.6$ & $4 I .1 \pm 14.7$ & $46.3 \pm 16.9$ & $<0.001 *$ \\
\hline $\begin{array}{l}\text { Psychiatric } \\
\text { comorbidity }\end{array}$ & $29(3.8)$ & I4 (2.7) & $15(6.3)$ & $0.015^{* *}$ \\
\hline Admission state & $250(32.7)$ & I 88 (35.7) & $62(26.1)$ & $0.008^{* *}$ \\
\hline $\begin{array}{l}\text { Duration of } \\
\text { current episode } \\
\text { (weeks) }\end{array}$ & $6.3 \pm 8.8$ & $5.6 \pm 6.7$ & $7.9 \pm 12.1$ & $0.006 *$ \\
\hline $\begin{array}{l}\text { Previous history } \\
\text { of mood episode }\end{array}$ & $563(73.7)$ & $40 \mathrm{I}(76.2)$ & I $62(68.1)$ & $0.018^{* *}$ \\
\hline $\begin{array}{l}\text { Illness duration } \\
\text { (years) }\end{array}$ & $17.2 \pm 17.1$ & $17.7 \pm 16.5$ & $16.1 \pm 18.5$ & NS \\
\hline $\begin{array}{l}\text { Previous history } \\
\text { of admission }\end{array}$ & 61.1 & 69.4 & 40.7 & $<0.00 I^{* *}$ \\
\hline $\begin{array}{l}\text { Number of } \\
\text { admissions }\end{array}$ & $3.1 \pm 1.9$ & $3.1 \pm 1.9$ & $3.2 \pm 2.1$ & NS \\
\hline $\begin{array}{l}\text { Previous psychotic } \\
\text { features }\end{array}$ & 47.2 & 57.1 & 22.8 & $<0.00 I^{* * *}$ \\
\hline
\end{tabular}

Notes: $* P<0.05$ by independent $t$-test; $* * P<0.05$ by Chi-squared test; data expressed as $\mathrm{n}(\%)$ or mean \pm standard deviation.

Abbreviations: BD-I, bipolar I disorder; BD-II, bipolar II disorder; NS, not significant.

$P=0.018)$ were more frequently coadministered to BD-II patients (Table 3 ).

\section{Evaluation of therapeutic efficacy}

The CGI-BP scores obtained at baseline, week four, and week eight were $4.3 \pm 0.9,3.5 \pm 0.9$, and $2.7 \pm 0.9$, respectively. The values were significantly lower at week four and eight than at baseline $(P<0.001)$. However, the difference between BD-I and BD-II patients was not significant (Figure 1).

Moreover, when the entire patient group was divided according to disease severity and the subgroups were further divided according to CGI-BP score, the number of patients with a higher level of symptom severity was significantly

Table 2 Daily dosages of quetiapine in patients with bipolar I and II disorder

\begin{tabular}{|c|c|c|c|c|}
\hline & $\begin{array}{l}\text { Total } \\
(n=764)(\%)\end{array}$ & $\begin{array}{l}\text { BD-I } \\
(n=526)(\%)\end{array}$ & $\begin{array}{l}\text { BD-II } \\
(n=238)(\%)\end{array}$ & $\boldsymbol{P}$-value* \\
\hline Day I & $197.5 \pm 182.5$ & $219.0 \pm 189.8$ & $149.6 \pm 155.4$ & $<0.001$ \\
\hline Week I & $250.5 \pm 208.9$ & $280.7 \pm 216.5$ & $183.3 \pm 173.5$ & $<0.001$ \\
\hline Week 2 & $301.2 \pm 232.9$ & $336.5 \pm 241.2$ & $222.4 \pm 191.4$ & $<0.001$ \\
\hline Week 4 & $327.7 \pm 228.0$ & $359.8 \pm 232.7$ & $256.0 \pm 199.7$ & $<0.001$ \\
\hline Week 8 & $349.0 \pm 231.5$ & $376.1 \pm 239.4$ & $289.1 \pm 201.0$ & $<0.001$ \\
\hline
\end{tabular}

Notes: $* P<0.001$ by independent $t$-test; data expressed as mean \pm standard deviation.

Abbreviations: BD-I, bipolar I disorder; BD-II, bipolar II disorder. 
Table 3 Concomitant psychotropic medications in patients with bipolar I and II disorder

\begin{tabular}{|c|c|c|c|c|}
\hline & $\begin{array}{l}\text { Total } \\
(n=764)\end{array}$ & $\begin{array}{l}\text { BD-I } \\
(n=526)\end{array}$ & $\begin{array}{l}\text { BD-II } \\
(n=238)\end{array}$ & $P$-value \\
\hline Total number of subjects & $559(73.2)$ & $182(76.5)$ & 377 (7I.7) & NS \\
\hline Mood stabilizers & $406(53.1)$ & $85(35.7)$ & $321(61.0)$ & $<0.00 I^{*}$ \\
\hline Anxiolytics & $195(25.5)$ & $75(31.5)$ & $120(22.8)$ & $0.011 *$ \\
\hline Antidepressants & $166(21.7)$ & I0I (42.4) & $65(12.4)$ & $<0.00 I^{*}$ \\
\hline Antipsychotics & $82(10.7)$ & $29(12.2)$ & $53(10.1)$ & NS \\
\hline Hypnotics and sedatives & $74(9.7)$ & $32(13.4)$ & $42(8.0)$ & $0.018^{*}$ \\
\hline \multicolumn{5}{|c|}{ Number of concomitant medications } \\
\hline One & $288(37.7)$ & $207(39.4)$ & $81(34.0)$ & NS \\
\hline Two & $189(24.7)$ & $118(22.4)$ & $71(29.8)$ & $0.028 * *$ \\
\hline Three & $72(3.4)$ & $50(9.5)$ & $22(9.2)$ & NS \\
\hline Four or more & $10(1.3)$ & $2(0.4)$ & $8(3.4)$ & $0.00 I^{*}$ \\
\hline
\end{tabular}

Notes: $* P<0.001$ by Chi-squared test; ${ }^{* * P}<0.05$ by Chi-squared test; data represents $n(\%)$.

Abbreviations: BD-I, bipolar I disorder; BD-II, bipolar II disorder; NS, not significant.

decreased after 4 and 8 weeks compared to that at baseline $(P<0.001)$. Such differences were also significant when the groups were compared after 4 and 8 weeks $(P<0.001$; Table 4).

When comparing the severity of symptoms at baseline, week four, and week eight by MADRS, there was a statistically significant decrease in severity for both the total MADRS value and every subscale score $(P<0.001)$. In addition, the severity of symptoms was not significantly different between BD-I and BD-II patients at baseline or after 4 and 8 weeks (Table 5).

The response rates $(\geq 50 \%$ reduction in the total MADRS value) at week four and eight were $25.5 \%$ and 58.9, respectively $(P<0.001)$, and the remission rates

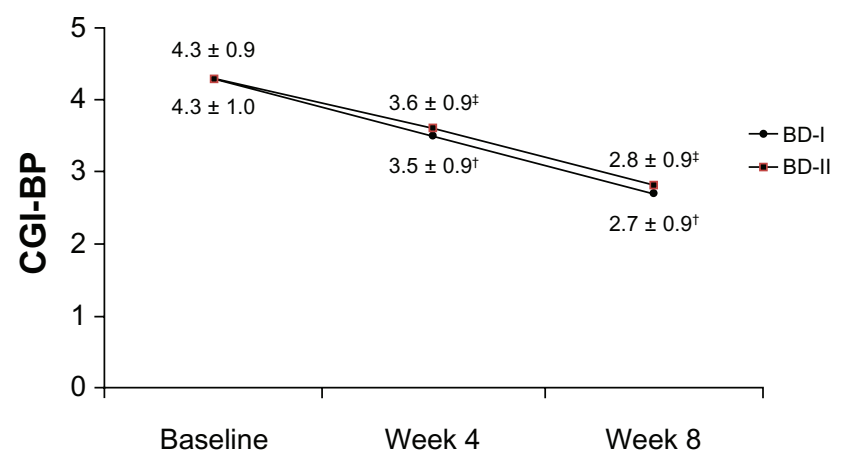

Figure I Changes of clinical global impression - bipolar version scores in patients with bipolar depression. $(n=764)$.

Notes: ${ }^{\dagger} P<0.00$ I by repeated measure analysis of variance in BD-I; $\ddagger P<0.00$ I by repeated measure analysis of variance in $\mathrm{BD}-\mathrm{Il}$; there was no significance (independent $t$-test) between BD-I and BD-II.

Abbreviations: BD-I, bipolar I disorder; BD-II, bipolar II disorder; CGI-BP, clinical global impression-bipolar version.
Table 4 Changes of subgroup of subjects in Clinical Global Impression - Bipolar scale in patients with bipolar I and II disorder $(\mathrm{n}=764)$

\begin{tabular}{lllll}
\hline CGI-BP subgroup & Baseline & 4 weeks & 8 weeks & P-value* \\
\hline Normal, not ill & $0(0.0)$ & $7(0.9)$ & $4 I(5.4)$ & $<\left.0.00\right|^{a-c}$ \\
Minimally ill & $0(0.0)$ & $82(10.8)$ & $287(37.6)$ & \\
Mildly ill & I $43(18.7)$ & $319(42.1)$ & $295(38.6)$ & \\
Moderately ill & $325(42.5)$ & $257(33.9)$ & $114(14.9)$ & \\
Markedly ill & $208(27.2)$ & $74(9.8)$ & $22(2.9)$ & \\
Severely ill & $70(9.2)$ & $17(2.2)$ & $4(0.5)$ & \\
Very severely ill & $18(2.4)$ & $\mathrm{I}(0.1)$ & $\mathrm{I}(0.1)$ & \\
\hline
\end{tabular}

Notes: $* P<0.001$ by Cochran-Mantel-Haenszel test; acomparison of baseline and 4 weeks; ${ }^{b}$ comparison of 4 weeks and 8 weeks; 'comparison of baseline and 8 weeks; data expressed as $n(\%)$.

Abbreviation: CGI-BP, Clinical Global Impression - Bipolar scale.

( $\leq 10$ in the total MADRS value) were $14.9 \%$ and $42.1 \%$, respectively $(P<0.001)$. However, there was no difference in the response and remission rates between BD-I and BD-II patients (Figure 2).

\section{Factors affecting the reduction of depressive symptom severity}

To determine the factors independently associated with MADRS reductions at week eight, age, illness duration, number of hospitalization, MADRS score at baseline, number of concomitant medications, duration of current episode, presence of remission on previous episode, and use of antidepressants were added in the regression model. MADRS score at baseline $(\beta=0.612, P<0.001)$, duration of current episode $(\beta=-0.152, P=0.001)$, and the presence of remission on previous episode $(\beta=0.111$, $P=0.012$ ) were significantly associated with improvements of depressive symptoms (Table 6).

Table 5 Changes of total Montgomery-Asberg Depression Rating Scale scores and subscores $(n=764)$

\begin{tabular}{|c|c|c|c|c|}
\hline & Baseline & 4 weeks & 8 weeks & $P$-value* \\
\hline Total scores & $30.1 \pm 10.6$ & $20.5 \pm 9.9$ & $14.0 \pm 9.5$ & $<0.001$ \\
\hline Apparent sadness & $3.1 \pm 1.2$ & $2.3 \pm 1.1$ & $1.5 \pm 1.1$ & $<0.001$ \\
\hline Reported sadness & $3.3 \pm 1.2$ & $2.3 \pm 1.2$ & $1.5 \pm 1.1$ & $<0.001$ \\
\hline Inner tension & $3.2 \pm 1.3$ & $2.3 \pm 1.2$ & $1.6 \pm 1.1$ & $<0.001$ \\
\hline Reduced sleep & $3.2 \pm 1.4$ & $1.8 \pm 1.3$ & $1.2 \pm 1.1$ & $<0.001$ \\
\hline Reduced appetite & $2.8 \pm 1.4$ & $1.8 \pm 1.3$ & $1.2 \pm 1.2$ & $<0.001$ \\
\hline $\begin{array}{l}\text { Concentration } \\
\text { difficulties }\end{array}$ & $3.1 \pm 1.3$ & $2.3 \pm 1.2$ & $1.7 \pm 1.1$ & $<0.001$ \\
\hline Lassitude & $3.1 \pm 1.3$ & $2.2 \pm 1.2$ & $1.6 \pm 1.1$ & $<0.001$ \\
\hline Inability to feel & $2.9 \pm 1.3$ & $2.1 \pm 1.2$ & $1.5 \pm 1.2$ & $<0.001$ \\
\hline Pessimistic thoughts & $3.1 \pm 1.4$ & $2.1 \pm 1.3$ & $1.5 \pm 1.2$ & $<0.001$ \\
\hline Suicidal thought & $2.3 \pm 1.6$ & $1.5 \pm 1.3$ & $0.9 \pm 1.1$ & $<0.001$ \\
\hline
\end{tabular}

Notes: $* P<0.001$ by repeated measure analysis of variance; data represented as mean \pm standard deviation. 


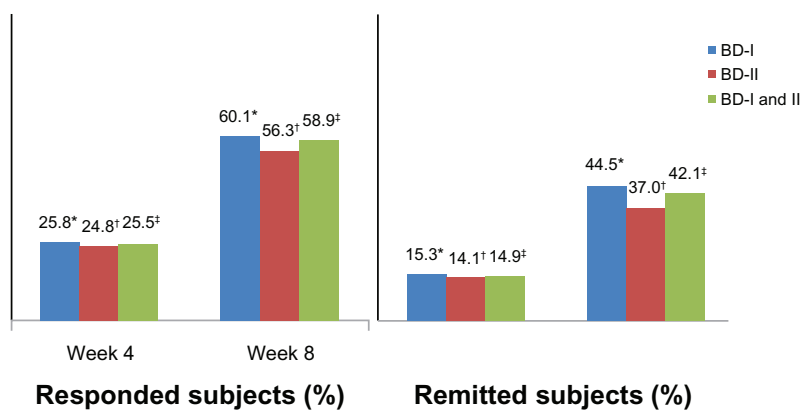

Figure 2 Response and remission rates by Montgomery-Asberg Depression Rating Scale score in bipolar I and II disorder patients. $(n=764)$.

Notes: $* P<0.00$ I by Chi square test between week 4 and 8 in BD-I; ${ }^{\dagger} P<0.00$ I by Chi square test between week four and eight in BD-II; $¥ P<0.00$ l by Chi square test between week four and eight in $\mathrm{BD}-\mathrm{I}$ and II; there was no significance (Chi square test) between BD-I and II.

Abbreviations: BD-I, bipolar I disorder; BD-II, bipolar II disorder; BD-I and II, bipolar I and II disorder.

\section{Therapeutic compliance and the adverse events}

To evaluate therapeutic compliance, the subjective level of therapeutic compliance was examined, and the results revealed compliance rates exceeding $75 \%$ after 4 weeks for 834 patients $(76.0 \%)$. In addition, after 8 weeks, the compliance level exceeded $75 \%$ for 827 patients (75.4\%). In excluded patients $(\mathrm{n}=333), 30.6 \%$ of BD patients $(\mathrm{n}=102)$ were admitted (BD-I $28.1 \%$ versus BD-II $35.8 \% ; P=0.108$ ). In addition, there was no significant difference in compliance between the BD-I and BD-II groups after 4 and 8 weeks (Table 7).

In total, 176 of $1097 \mathrm{BD}$ patients (16.0\%) felt fatigued, and 165 patients (14.9\%) reported somnolence during the study period. The mean weight change throughout the study was $1.4 \pm 2.6 \mathrm{~kg}$.

Manic/hypomanic episodes were observed in seven cases (three cases/four cases; $0.6 \%$ ) and three cases (three cases/ none; $0.3 \%$ ) at week four and eight, respectively. Only four

Table 6 Factors associated with Montgomery-Asberg Depression Rating Scale score reductions at week eight $(n=764)$

\begin{tabular}{llll}
\hline Variables & $\beta$ & $\boldsymbol{t}$ & P-value \\
\hline Age & 0.076 & 1.766 & 0.078 \\
Illness duration & 0.007 & 0.162 & $0.87 \mathrm{I}$ \\
Hospitalization number & 0.005 & 0.116 & 0.907 \\
MADRS score at baseline & 0.612 & 14.266 & $<0.00 I^{*}$ \\
Number of concomitant medication & 0.060 & 1.392 & 0.165 \\
Duration of current episode & -0.152 & -3.472 & $0.00 I^{*}$ \\
Presence of remission on previous episode & 0.111 & 2.524 & $0.012^{* *}$ \\
Use of antidepressants & 0.041 & 1.144 & 0.253 \\
\hline
\end{tabular}

Notes: $* P<0.05$ by multiple linear regression; $* * P<0.05$ by dummy variable regression.

Abbreviation: MADRS, Montgomery-Asberg Depression Rating Scale. of the patients who exhibited manic/hypomanic episodes had symptom severities exceeding moderately ill according to the CGI-BP score after 4 weeks, and only one patient had to terminate quetiapine therapy. In addition, the symptoms could only be controlled by adjusting the dose of quetiapine and concomitant medications in all of the remaining cases.

\section{Discussion}

Active treatment of depressive symptoms may be very important in patients with BD because many BD patients attempt to commit suicide during the depressive episode or mixed episode including depressive symptoms, and the risk of committing suicide is 15 -fold greater in $\mathrm{BD}$ patients than in the general population. ${ }^{16}$ Generally, in patients with bipolar depression, the use of atypical antipsychotics was limited to patients exhibiting psychotic symptoms. However, the use of atypical antipsychotics has been accepted as a new treatment modality because recent studies have demonstrated the therapeutic efficacy of atypical antipsychotics in treating bipolar depression, regardless of the accompanying psychotic symptoms. ${ }^{12,13,17-20}$ In addition, the Korean Medication Algorithm Project for BD 2006 (KMAP-BP 2006) recommended the combined use of atypical antipsychotics and mood stabilizers in the treatment of $\mathrm{BD}$, regardless of the presence or absence of psychotic symptoms. ${ }^{10}$

In the current study, treatment with the atypical antipsychotic quetiapine after 4 and 8 weeks resulted in noticeable improvements in depressive symptoms in both BD-I and BD-II patients compared to the baseline findings. In addition, when disease severity was classified according to the CGI-BP score, the number of patients with more severe symptoms was decreased after both 4 and 8 weeks of treatment. In particular, such a change was observed between 4 and 8 weeks of treatment, which suggests that the therapeutic effectiveness of quetiapine continuously increased for at least 8 weeks. The improvement of depressive symptoms was consistently observed on every subscale of MADRS, and this result is consistent with the results of previous double-blind, randomized controlled trials. ${ }^{12,13} \mathrm{In}$ addition, the rates of response and remission continuously increased for 8 weeks, resulting in values of $58.9 \%$ and $42.1 \%$, respectively. These results can be considered to support the results of previous studies and indicate that quetiapine may be effective in the treatment of bipolar depression. ${ }^{12,13,21}$

BD-II patients were more chronically ill, they had a greater duration of illness and spent more time in partial remission and less time in full remission. ${ }^{22}$ In the current study, however, there were no differences in the response 
Table 7 Compliance of quetiapine treatment in patients with bipolar I and II disorder

\begin{tabular}{|c|c|c|c|c|c|c|c|}
\hline & \multicolumn{3}{|l|}{ Week 4} & \multicolumn{3}{|l|}{ Week 8} & \multirow[t]{2}{*}{$P$-value } \\
\hline & $\begin{array}{l}\text { Total } \\
(n=1097)\end{array}$ & $\begin{array}{l}\text { BD-I } \\
(n=743)\end{array}$ & $\begin{array}{l}\text { BD-II } \\
(n=354)\end{array}$ & $\begin{array}{l}\text { Total } \\
(n=1097)\end{array}$ & $\begin{array}{l}\text { BD-I } \\
(n=743)\end{array}$ & $\begin{array}{l}\text { BD-II } \\
(n=354)\end{array}$ & \\
\hline$<25 \%$ & $15(1.4)$ & II (I.5) & $4(1.1)$ & $29(2.6)$ & $16(2.2)$ & $13(3.7)$ & NS \\
\hline $25 \%-50 \%$ & $48(4.4)$ & $31(4.2)$ & $17(4.8)$ & 43 (3.9) & $27(3.6)$ & $16(4.5)$ & NS \\
\hline $50 \%-75 \%$ & $200(18.2)$ & $|4|(19.0)$ & $59(16.7)$ & $198(18.1)$ & 132 (I7.8) & $66(18.6)$ & NS \\
\hline$>75 \%$ & $834(76.0)$ & $560(75.4)$ & $274(77.4)$ & $827(75.4)$ & $568(76.5)$ & $259(73.2)$ & NS \\
\hline
\end{tabular}

Note: Statistical analysis was done by Cochran-Mantel-Haenszel test and Chi-squared test.

Abbreviations: BD-I, bipolar I disorder; BD-II, bipolar II disorder; NS, not significant.

and remission rates measured by MADRS between the BD-I and BD-II groups throughout the entire observation period. These results were concurrent with the results of a previous naturalistic study indicating that the treatment outcome of depressive symptoms was not different between the BD-I and BD-II patients. ${ }^{23}$ This suggested that quetiapine could be used effectively in both BD-I and BD-II patients.

The mean initial daily dose of quetiapine was $197.5 \mathrm{mg}$, and this was higher than the $50 \mathrm{mg} /$ day dose of quetiapine monotherapy administered in previous studies. ${ }^{12,13}$ In addition, the percentage of patients treated with a combination of psychotropic agents was $73.2 \%$, which was relatively high. This discrepancy is thought to be due to the fact that previous studies were conducted in outpatients, whereas $32.7 \%$ of the subjects in the current study were inpatients. In addition, $81.3 \%$ of the patients had a level of disease severity greater than moderately ill, and thus patients with relatively severe symptoms were more abundant in this study than in previous studies. Furthermore, previous studies were conducted as randomized controlled trials, and the primary aim of the current study was to observe patients in an actual clinical setting. The mean daily dose of quetiapine was increased slowly from the beginning of administration to $327.7 \mathrm{mg}$ and $349.0 \mathrm{mg}$ after 4 and 8 weeks, respectively, which is in agreement with the results of previous studies demonstrating that therapeutic efficacy was significant with daily doses of $300 \mathrm{mg}$ or $600 \mathrm{mg} .{ }^{12,13,21}$

On the other hand, throughout the entire period of observation in the current study, the dose of quetiapine was lower in the BD-II patients than in the BD-I patients; however, there was no difference in treatment outcomes. One reason may be that the ratio of combination therapy was higher in BD-II patients than in BD-I patients, and this combination therapy might be countervailing the lower dose of quetiapine.

In fact, it was found that - with the exception of mood stabilizers - combination therapy with antidepressants, anxiolytics, and hypnotics was administered more frequently to BD-II patients. This is thought to be due to the fact that the diagnosis of psychiatric comorbidity is more common in BD-II patients, ${ }^{22}$ and in the current study, psychiatric comorbidity was more prevalent in patients with BD-II. However, there was no difference in the number of patients administered combination therapy between the two disease groups $(71.7 \%$ versus $76.5 \% ; P=0.186)$, and the number of concomitant medications $(\beta=0.060, P=0.165)$ and the use of antidepressants $(\beta=-0.041, P=0.253)$ did not affect MADRS changes.

Evaluation of therapeutic compliance in BD patients has been considered difficult. ${ }^{24} \mathrm{BD}$ patients tend to evaluate their own therapeutic compliance as being high, and the pill count method or the measurement of drug concentration also has limitations in the accurate evaluation of therapeutic compliance..$^{25}$ In the current study, the subjective level of therapeutic compliance was evaluated after 4 and 8 weeks of treatment, and a compliance rate exceeding $75 \%$ was observed for approximately $70 \%$ of the study population; thus, the rate of therapeutic compliance was higher than in previous studies. ${ }^{26,27}$ This is thought to be attributable to several factors, including the fact that the current study was an observational study allowing for the dose of quetiapine to be adjusted freely, the lack of restriction on the use of concomitant medications, the large percentage of inpatients in the study population, and the relatively short period of observation.

It has been reported that in the treatment of $\mathrm{BD}$, quetiapine tends to exert antidepressant effects with mild adverse events. In the current study, the level of adverse events was not evaluated systemically, but the rates of fatigue, somnolence, and dropout were $16.0 \%, 14.9 \%$, and $3.6 \%$, respectively. This result was comparable to those of previous studies. ${ }^{11,28,29}$ However, the detected dropout rate was extremely low compared to the rate of $16.0 \%$ observed in the monotherapy group administered a comparable daily dose $(300 \mathrm{mg})$. This arose from the lack of strict restriction in the protocol. 
Conversely, one of the difficulties encountered in the treatment of bipolar depression is manic/hypomanic switching. In the current study, the incidences of manic/ hypomanic episodes after 4 and 8 weeks were $0.6 \%$ and $0.3 \%$, respectively, which were lower than those reported previously. ${ }^{12,13,21}$ Although the current study was an openlabel observational study, the research protocol was not strict, and the study was conducted with a relatively short period of observation; these results suggest that quetiapine could be used safely for the treatment of bipolar depression from the viewpoint of adverse events.

This was a large-scale study to examine the therapeutic efficacy of quetiapine in patients with BD-I and BD-II depression in an actual clinical setting. However, this study has several limitations. A structural interview was not performed. It was an open-label observational study permitting the flexible adjustment of the dose of quetiapine and the use of concomitant medications, and thus the control of variables contributing to the improvement of symptoms was difficult. Also, the investigation of adverse events was not systematic in this study. However, the use of a detailed checklist for adverse events was beyond the scope of this paper. Therefore, additional studies for the safety of quetiapine will be needed.

\section{Conclusion}

The results of this study demonstrated that the treatment of BD-I and BD-II depression with quetiapine for 8 weeks had significant antidepressant effects in an actual clinical setting, and the therapeutic efficacy improved with time, with minimal manic switching. In addition, the clinical improvement was similar in both BD-I and BD-II patients. However, the mean dosage of quetiapine was lower in BD-II patients throughout the observational periods, and the combination therapy with antidepressants, anxiolytics, and hypnotics was more frequently administered to BD-II patients.

\section{Acknowledgment}

This study was funded by AstraZeneca.

\section{Disclosure}

The authors report no conflicts of interest in this work.

\section{References}

1. American Psychiatric Association. Diagnostic and Statistical Manual of Mental Disorders, 4th Edition, Text Revision: DSM-IV-TR ${ }^{\circledR}$. Washington, DC: American Psychiatric Association; 2000.

2. Shastry BS. Bipolar disorder: an update. Neurochem Int. 2005;46(4): 273-279.
3. Judd LL, Akiskal HS, Schettler PJ, et al. The long-term natural history of the weekly symptomatic status of bipolar I disorder. Arch Gen Psychiatry. 2002;59(6):530-537.

4. Kupfer DJ, Frank E, Grochocinski VJ, Cluss PA, Houck PR, Stapf DA. Demographic and clinical characteristics of individuals in a bipolar disorder case registry. J Clin Psychiatry. 2002;63(2):120-125.

5. Sachs GS, Printz DJ, Kahn DA, et al. The expert consensus guideline series: medication treatment of bipolar disorder 2000. Postgrad Med. 2000;Spec No:1-104.

6. Min KJ, Shin YC, Jon DI, Yoon BH, Kwon JS, Bahk WM. Korean medication algorithm for bipolar disorder (III): depressive episode. Korean J Psychopharmacol. 2003;14(4):336-346.

7. Post RM, Calabrese JR. Bipolar depression: the role of atypical antipsychotics. Expert Rev Neurother. 2004;4(6 Suppl 2):S27-S33.

8. Yatham LN, Kennedy SH, O'Donovan C, et al. Canadian Network for Mood and Anxiety Treatments (CANMAT) guidelines for the management of patients with bipolar disorder: consensus and controversies. Bipolar Disord. 2005;7(Suppl 3):5-69.

9. Yatham LN, Kennedy SH, O'Donovan C, et al. Canadian Network for Mood and Anxiety Treatments (CANMAT) guidelines for the management of patients with bipolar disorder: update 2007. Bipolar Disord. 2006;8(6):721-739.

10. Min KJ, Bahk WM, Seo JS, et al. Korean medication algorithm for bipolar disorder 2006 (III): depressive episode. Korean $J$ Psychopharmacol. 2006;17:436-448.

11. Sajatovic M, Mullen JA, Sweitzer DE. Efficacy of quetiapine and risperidone against depressive symptoms in outpatients with psychosis. J Clin Psychiatry. 2002;63(12):1156-1163.

12. Calabrese JR, Keck PE Jr, Macfadden W, et al. A randomized, doubleblind, placebo-controlled trial of quetiapine in the treatment of bipolar I or II depression. Am J Psychiatry. 2005;162(7):1351-1360.

13. Thase ME, Macfadden W, Weisler RH, et al. Efficacy of quetiapine monotherapy in bipolar I and II depression: a double-blind, placebocontrolled study (the BOLDER II study). J Clin Psychopharmacol. 2006;26(6):600-609.

14. Spearing MK, Post RM, Leverich GS, Brandt D, Nolen W. Modification of the Clinical Global Impressions (CGI) Scale for use in bipolar illness (BP): the CGI-BP. Psychiatry Res. 1997;73(3):159-171.

15. Montgomery SA, Asberg M. A new depression scale designed to be sensitive to change. Br J Psychiatry. 1979;134:382-389.

16. Harris EC, Barraclough B. Suicide as an outcome for mental disorders. A meta-analysis. Br J Psychiatry. 1997;170:205-228.

17. Vieta E, Gasto C, Colom F, et al. Role of risperidone in bipolar II: an open 6-month study. J Affect Disord. 2001;67(1-3):213-219.

18. Montgomery SA. Dopaminergic deficit and the role of amisulpride in the treatment of mood disorders. Int Clin Psychopharmacol. 2002; 17(Suppl 4):S9-S15.

19. Tohen M, Vieta E, Calabrese J, et al. Efficacy of olanzapine and olanzapine-fluoxetine combination in the treatment of bipolar I depression. Arch Gen Psychiatry. 2003;60(11):1079-1088.

20. Sachs G, Sanchez R, Marcus R, et al. Aripiprazole in the treatment of acute manic or mixed episodes in patients with bipolar I disorder: a 3-week placebo-controlled study. J Psychopharmacol. 2006;20(4): 536-546.

21. Young AH, McElroy SL, Bauer M, et al. A double-blind, placebocontrolled study of quetiapine and lithium monotherapy in adults in the acute phase of bipolar depression (EMBOLDEN I). J Clin Psychiatry. 2010;71(2):150-162.

22. Judd LL, Akiskal HS, Schettler PJ, et al. The comparative clinical phenotype and long term longitudinal episode course of bipolar I and II: a clinical spectrum or distinct disorders? JAffect Disord. 2003; 73(1-2):19-32.

23. Mantere O, Suominen K, Valtonen HM, et al. Differences in outcome of DSM-IV bipolar I and II disorders. Bipolar Disord. 2008;10(3): 413-425.

24. Colom F, Vieta E. Non-adherence in psychiatric disorders: misbehaviour or clinical feature? Acta Psychiatr Scand. 2002;105(3):161-163. 
25. Vieta E. Improving treatment adherence in bipolar disorder through psychoeducation. J Clin Psychiatry. 2005;66(Suppl 1):24-29.

26. Maarbjerg K, Aagaard J, Vestergaard P. Adherence to lithium prophylaxis: I. Clinical predictors and patient's reasons for nonadherence. Pharmacopsychiatry. 1988;21(3):121-125.

27. Colom F, Vieta E, Martinez-Aran A, Reinares M, Benabarre A, Gasto C. Clinical factors associated with treatment noncompliance in euthymic bipolar patients. J Clin Psychiatry. 2000;61(8):549-555.
28. Bowden CL, Grunze H, Mullen J, et al. A randomized, double-blind, placebo-controlled efficacy and safety study of quetiapine or lithium as monotherapy for mania in bipolar disorder. J Clin Psychiatry. 2005; 66(1):111-121.

29. McIntyre RS, Brecher M, Paulsson B, Huizar K, Mullen J. Quetiapine or haloperidol as monotherapy for bipolar mania - a 12-week, doubleblind, randomised, parallel-group, placebo-controlled trial. Eur Neuropsychopharmacol. 2005;15(5):573-585.

\section{Publish your work in this journal}

Neuropsychiatric Disease and Treatment is an international, peerreviewed journal of clinical therapeutics and pharmacology focusing on concise rapid reporting of clinical or pre-clinical studies on a range of neuropsychiatric and neurological disorders. This journal is indexed on PubMed Central, the 'PsycINFO' database and CAS.
The manuscript management system is completely online and includes a very quick and fair peer-review system, which is all easy to use. Visit http://www.dovepress.com/testimonials.php to read real quotes from published authors.

Submit your manuscript here: http://www.dovepress.com/neuropsychiatric-disease-and-treatment-journal 